\title{
Um estudo sobre o amor: Diálogos entre Sigmund Freud e Erich Fromm
}

\author{
A study on love: Dialogues between Sigmund Freud and Erich Fromm
}

Adriano Schlösser ${ }^{[a]}$, Daniel David Dalfovo ${ }^{[b]}$, Josiane Delvan da Silva Delvan ${ }^{[c]}$

\footnotetext{
[a] Acadêmico do curso de Psicologia da Universidade do Vale do Itajaí (Univali), Joinville, SC - Brasil, e-mail: adriano. psicologia@yahoo.com.br

${ }^{[b]}$ Acadêmico do curso de Psicologia da Universidade do Vale do Itajaí (Univali), Balneário Camboriú, SC - Brasil.

${ }^{[c]}$ Docente do curso de Psicologia da Universidade do Vale do Itajaí (Univali), Itajaí, SC - Brasil, e-mail: josidelvan@univali.br
}

Recebido: $17 / 03 / 2011$ Received: 03/17/2011

Aprovado: $28 / 07 / 2011$ Approved: 07/28/2011

\section{Resumo}

Ao refletir-se sobre o amor na contemporaneidade, percebe-se que a configuração dos vínculos afetivo-amorosos vem sofrendo grandes transformações na atualidade, na qual a lógica consumista - uso e descarte - tem-se aplicado também às relações amorosas, valorizando-se a troca rápida de parceiros acima da manutenção dos relacionamentos. Tais mudanças tiveram impacto também na clínica psicanalítica, que tem a transferência como peça fundamental para sua realização, ou seja, necessita de um vínculo duradouro em que o analisando deposita sua libido e confiança na figura do analista, que só assim poderá direcionar essa libido possibilitando o processo psicanalítico. Com efeito, o presente trabalho teve por objetivo geral investigar o amor na abordagem psicanalítica a partir de Sigmund Freud e Erich Fromm, visando o desenvolvimento de um diálogo epistemológico entre esses dois autores acerca do amor, pontuando as aproximações e os distanciamentos conceituais identificados a partir da leitura e análise de suas obras. Como resultados, a literatura indicou que Fromm concebe o amor como uma arte, como uma atitude perante a vida, não abarcando, dessa forma, um caráter de exclusividade. Freud, em contrapartida, identifica o amor como o depósito da libido em um objeto, associando-o a aspectos pulsionais que estão a serviço de um ideal narcísico perdido.

Palavras-chave: Amor. Psicanálise. Transferência. Relacionamento.

\section{Abstract}

When reflecting upon love in contemporary society one realizes that the configuration of affective bonds is experiencing major transformations, in which the logics of consumism - both use and disposal - has also been applied to romantic relationships, valuing the fast exchange of partners over the maintenance of relationships. These changes also had an impact on psychoanalytic practice, and it holds the same transfer as key to its realization, that is, it needs a durable bond in which the analyzed person puts his libido and confidence in the person of the analyst who, only then, is able to direct that libido allowing the psychoanalytic process. Indeed, this study aimed to investigate love from Sigmund Freud's and Erich Fromm's psychoanalytic approach, in order to develop an epistemological dialogue between these two authors about love, pointing out the conceptual approaches and the distances identified by the reading and analysis of their works.

Psicol. Argum. 2012 jul./set., 30(70), 567-573 
As a result, literature appointed that Fromm conceives love as an art, as an attitude before life, thus not covering an exclusivity character. Freud, by contrast, identifies love as the deposit of libido in an object, associating it to pulsional aspects that are at the service of a lost narcissistic ideal.

Keywords: Love. Psychoanalysis. Transference. Relationships.

\section{Introdução}

A escolha deste tema deu-se por causa da importância que o amor tem na vida das pessoas como experiência humana elementar, sendo este buscado e expresso por meio das relações cotidianas, bem como de músicas, filmes e livros. 0 amor, então, faz parte da vida das pessoas e é força atuante na sociedade.

Existem diversas formas de concepção do amor, porém, neste trabalho, tomaremos como base Sigmund Freud e Erich Fromm, buscando explorar suas concepções acerca do tema, sendo que ele também tem grande relevância na teoria psicanalítica.

0 amor, na clínica psicanalítica - também chamado de transferência - é peça fundamental para que o processo terapêutico psicanalítico possa acontecer. Ele unifica o laço entre o paciente e o analista, que, por meio da potência do amor, explora o inconsciente do primeiro, dando possibilidade de o tratamento acontecer (Brito \& Besset, 2008).

Freud, a partir de sua metapsicologia do amor, enfatiza o caráter repetitivo e regressivo deste, dizendo que, por sua natureza narcísica, o amor aspira um reencontro impossível com os primeiros objetos introjetados da criança (Lejarraga, 2002).

A partir da leitura da obra $A$ arte de amar, de Erich Fromm (1991), nos deparamos com uma concepção de amor ímpar. Para este autor, o amor é visto como uma arte, que precisa ser aprendida na teoria e desenvolvida na prática, necessitando de conhecimento, disciplina e esforço, entre outras coisas, como em qualquer arte, para que se possa obter êxito em sua prática, até que se torne algo natural no ser humano.

Percebemos que o amor, para Freud, era peça fundamental na compreensão dos casos clínicos da doença de sua época - a histeria (Paz, 2009). Nos tempos de Fromm (1991), o amor foi visto como um fenômeno em desintegração, mas de extrema importância na vida e na saúde das pessoas. Nos dias atuais, o amor continua sendo tema importantíssimo para a compreensão dos seres humanos e seus relacionamentos afetivos, pois a queixa de dificuldades de relacionamento na vida das pessoas é cada vez mais frequente (Rios, 2008).

Com efeito, o presente trabalho consiste em uma pesquisa bibliográfica e tem como objetivo geral investigar o amor na abordagem psicanalítica a partir de Sigmund Freud e Erich Fromm, buscando desenvolver diálogos entre os dois autores acerca do amor, pontuando as aproximações e os distanciamentos conceituais identificados por meio da leitura e análise de suas obras.

\section{Desenvolvimento}

\section{0 conceito de amor em Sigmund Freud}

O termo "amor" não foi definido como um conceito na obra de Freud, pois foi utilizado pelo autor de diferentes formas de acordo com as articulações e o momento em que estava em sua construção histórica (Paz, 2009). Porém faremos um esforço objetivando identificar a percepção de Freud acerca do tema.

Com base no estudo realizado por Paz (2009), as primeiras referências de Freud ao fenômeno amoroso são encontradas em seus relatos clínicos de casos de histeria, em que o autor vê amor como sinônimo de sexualidade. Dos estudos sobre a histeria, Freud tira importantes conclusões com relação ao lugar do amor na neurose histérica, observando que um ponto em comum entre essas pacientes é a excessiva busca de amor, que, na infância, era intensamente despendido a elas por seus pais, sendo que o traço principal de suas pacientes histéricas é que elas são insaciáveis por amor. Sendo assim, Freud reconheceu na neurose a presença de uma ânsia de amor que nesse momento, para ele, era equivalente à ânsia sexual.

Ao identificar um determinante infantil tanto à neurose quanto ao amor, Freud elabora seu 
conceito de amor de transferência, concluindo que o amor consiste na tentativa de reedição das primeiras relações amorosas infantis registradas, caracterizando-se por um depósito da libido em um objeto específico.

Assim, surge também o conceito de transferência como peça decisiva no trabalho analítico, em que o analista é substituto das figuras parentais do paciente e é depositário de seu investimento libidinal. Caberá, então, ao analista, seguir o caminho dessa libido, utilizando-se dessa confiança depositada, pelo paciente, nele, para o desenvolvimento do trabalho analítico (Brito \& Besset, 2008). Assim, o setting terapêutico se dispõe a ser o lugar, no tempo e no espaço, onde as manifestações das fases anteriores são permitidas e desejadas, objetivando que essas sejam trabalhadas (Ferreira, 2006).

Em 1905, nos Três ensaios sobre a teoria da sexualidade, Freud (1996) pontua que o primeiro e mais importante vínculo sexual dá-se no contato do bebê com a mãe, durante a amamentação, onde a mãe, com suas expressões de ternura, desperta a pulsão sexual de seu filho e mais tarde qualquer busca amorosa é a busca desse primeiro objeto de amor. Ainda nessa obra, o autor diferencia a parcialidade da relação objetal que se dá pela pulsão do amor - ainda que ambos estejam fortemente ligados - vendo o amor como uma supervalorização objetal que proporciona uma ideia de globalidade ou unidade do objeto.

No seu texto Sobre o narcisismo: uma introdução, Freud (1969) traz o amor estreitamente ligado ao ideal narcísico, sendo esse o meio pelo qual o sujeito tenta reencontrar seu narcisismo primário - fase essa em que o eu é o reservatório da libido, sendo investido de todos os ideais parentais e perfeição - e toda a sua onipotência perdida. Tendo visto isso, Freud propôs dois tipos de escolhas objetais possíveis: a anaclítica ou de ligação, e a narcísica.

Sendo assim, na escolha objetal anaclítica, o sujeito buscará um substituto para seus primeiros objetos sexuais, no caso as suas figuras parentais, que são as pessoas que se preocupam com sua alimentação, cuidado e proteção. No tipo narcísico de escolha objetal, o indivíduo toma como modelo seus próprios "eus" e escolhe seu objeto de desejo por ver nesse objeto: o que ele próprio é; o que ele próprio foi; o que ele gostaria de ser; alguém que foi uma vez parte dela mesma. 0 último modelo diz respeito à mulher com relação a um filho que, ao gerá-lo, passa a amá-lo de forma narcísica por ela um dia ter sido uma parte dela (Freud, 1969). Porém, não há uma separação precisa entre os dois modos de escolha objetal, mas diferentes medidas, tendências e inclinações em cada sujeito, sendo que os dois se mantêm em funcionamento ao longo de sua vida (Rios, 2008).

Em sua carta a Einstein, quando Freud (1988) propõe um conflito entre as forças Eros e Thanatos, define Eros como instintos humanos eróticos ou sexuais, que tendem a preservar e a unir, e Thanatos como instintos que tendem a destruir e a matar. Mais adiante, Freud faz uma relação de Eros e Thanatos com a popular oposição entre amor e ódio. Aqui, mais uma vez, podemos encontrar o amor relacionado com pulsão e com a unicidade. Para Freud, é por meio do amor entre dois seres humanos que Eros revela o seu intuito que é, de mais de um, fazer um único, ou seja, sua força para unificar (Freud, 1988).

Desta forma, podemos identificar que Freud apresenta o conceito de amor marcado por uma tensão, estando esse em determinados momentos ligado a aspectos do ego e seu ideal narcísico, e em outros momentos ligado a pulsão.

\section{0 conceito de amor em Erich Fromm}

Os apontamentos que seguem foram elaborados a partir da leitura e análise da obra $A$ arte de Amar (Fromm, 1991), considerada fundamental, pois apresenta as reflexões do autor sobre o tema em questão.

Segundo Erich Fromm, o amor não é, necessariamente, uma relação com uma pessoa específica, mas uma orientação de caráter que determina a relação de alguém com o mundo. Para ele a palavra "amor" não deve ser utilizada para qualquer tipo de união interpessoal. Considerando-se que a união pode ser obtida de diversos modos, essa palavra deve ser reservada somente para um tipo específico de união: a união madura que existe sob condição da preservação da integridade própria, ou seja, a união com a preservação da individualidade de ambos os amantes.

Para Fromm, o amor, em sua forma madura, é uma atividade, uma expressão de produtividade e não um afeto passivo, podendo esse caráter ativo do amor ser descrito primordialmente em dar e não em receber. Para este autor, a base da nossa necessidade de amar está na experiência de separação e na necessidade resultante de superar a ansiedade dessa 
experiência pela experiência da união. Além disso, existem alguns elementos básicos comuns a todas as formas de amor, são eles: cuidado, responsabilidade, respeito e conhecimento, e apenas com essas qualidades o amor pode ser considerado maduro.

Fromm (1991, p. 38) utiliza o amor de mãe para filho como exemplo mais explícito de que o amor implica em cuidado. "Amor é preocupação ativa pela vida e crescimento daquilo que amamos". Portanto, para ele, não se pode ter amor sincero por alguém sem que por esse se tenha cuidado. Cuidado e preocupação implicam em outro aspecto do amor, o da responsabilidade. Esta foi vista por Fromm, em seu verdadeiro sentido, como um ato inteiramente voluntário de estar pronto a responder pelas necessidades, físicas ou psíquicas, expressas ou não, do ser amado.

Contudo a responsabilidade poderia facilmente corromper-se em dominação ou em possessividade, se não fosse o terceiro aspecto do amor: o respeito, que o autor explica como sendo a capacidade de o amante ver o amado, tal como ele é, conhecendo sua singularidade e não fazendo deste, objeto de seu uso próprio.

0 respeito só existe com base na liberdade e não na dominação, entretanto respeitar uma pessoa não é possível sem conhecê-la. Esse conhecimento que se caracteriza como um aspecto do amor é aquele que, segundo Fromm, penetra no âmago do ser amado, apenas sendo possível quando o amante consegue transcender a preocupação por si mesmo passando a ver o outro nos próprios termos deste.

Fromm traz ainda diversas formas de amor, entre elas: amor fraterno, amor materno, amor erótico, amor próprio e amor de Deus.

0 amor fraterno abrange todas as qualidades anteriormente citadas com relação a todo e qualquer ser humano, caracterizando-se pela falta de exclusividade. Esse amor baseia-se na experiência de que todos somos um, assim sendo denominado de amor entre iguais.

Já o amor materno caracteriza-se como uma afirmação incondicional da vida do filho e de suas necessidades. Nesse caso, a mãe, além de suprir as necessidades fisiológicas da criança, por exemplo, dar-lhe leite, terá a função de instalar na criança o que Fromm chamou de "amor pela vida", sendo que este, estando presente na mãe, será certamente passado para o filho. A relação mãe-filho é, ao contrário do amor fraterno, desigual, por ser uma relação onde um necessita de toda ajuda que o outro dá, tendo assim um caráter altruísta.
O amor erótico, diferente dos dois tipos anteriores, é o anseio de fusão completa, de união com outra pessoa, portanto é exclusivo e caracteriza-se como a forma mais enganosa de amor que existe. Confunde-se muitas vezes com o que Fromm chamou de "cair" enamorado, ou apaixonar-se, que é uma experiência de súbita intimidade e tem, por sua própria natureza, vida curta. Pode também ser confundido pelo que o autor chamou de "egoísmo a dois", que são duas pessoas "amando-se" uma a outra, sem sentirem amor por mais ninguém, pois essas duas pessoas se identificam mutuamente e resolvem o problema da separação ampliando em dois o singular individual. A condição para que o amor erótico seja real, é que ele também seja amor fraterno, apenas excluindo os outros no sentido de fusão erótica. "O amor erótico é exclusivo, mas ama na outra pessoa toda a humanidade, tudo quanto vive" (Fromm, 1991, p. 71).

Para ele, o amor próprio é conjuntivo ao amor fraterno - o amor que antecede qualquer outra forma de amor - portanto, sendo que não existe conceito de homem em que uma pessoa não esteja incluída, se ela não amar a si mesma, não será capaz de amar a qualquer outro ser.

Fromm discorre ainda a forma religiosa do amor, que ele chamou de amor de Deus, representando em qualquer religião, seja ela teísta ou ateísta - o bem mais desejável. 0 caráter desse amor vai estar diretamente ligado ao peso dos aspectos matriarcais (representado por um amor incondicional e compassivo) ou patriarcais (compreendido como um amor exigente, justo, que pode punir ou recompensar) de cada religião, sendo que o homem projetará tais aspectos para determinar esse amor.

\section{Diferencas e semelhancas entre \\ Freud e Fromm na concepç̃o do amor}

Nesta categoria, procurou-se esclarecer como Freud e Erich Fromm apresentam suas ideias sobre o amor. Apesar de este tema ter sido de grande importância na obra de ambos os autores, foi visto por cada um deles de maneira diferente, porém com alguns pontos em comum.

Freud é herdeiro de uma visão de amor comum ao final do século passado, na qual a imagem de amor é indissociável do amor romântico (Lejarraga, 2002). Para compreender-se melhor essa concepção de amor romântico, nos remeteremos a Platão, 
que, por meio do discurso de Aristófanes, recorre a um antigo mito, no qual, há tempos atrás, teriam existido seres esféricos que eram formados por dois homens, duas mulheres ou um homem e uma mulher, e em um dado momento, esses seres foram divididos pelos deuses, tornando-se, então, de um, dois. Assim, a partir dessa divisão, cada metade sai em busca da outra, objetivando obter novamente sua completude perdida, retornando a seu estado original, em que eram um ser único e perfeito (Brito \& Besset, 2008). Dessa forma, Freud parte de uma visão romântica de amor, quando nos aponta este como uma tentativa de reedição da felicidade perdida na fase do narcisismo primário, visto que o amor romântico baseia-se na busca do objeto ideal que irá complementar o sujeito (Paz, 2009).

Porém, em $O$ mal estar da civilização, Freud (1988) afirma ser impossível um encontro absoluto entre sujeito e objeto, estando, assim, essa busca amorosa fadada ao fracasso. Para ele, crer na possibilidade de tornar-se um só com um parceiro é tido como "ilusão amorosa", e "é justamente pela falta e pela ilusão amorosa que é possível o surgimento da transferência" (Brito \& Besset, 2008, p. 694), sendo essa a busca no objeto amoroso de algo que falta no amante (Speller, 2001).

Erich Fromm (1991) esclarece que o desejo de fusão interpessoal é o mais poderoso desejo do homem, sendo a separação, fonte de intensa ansiedade. Além disso, esta também dá origem ao sentimento de culpa e a vergonha. Para explicar isso, Fromm recorreu ao mito bíblico de Adão e Eva, no qual, depois de eles terem desobedecido às leis celestes - pois não há bem nem mal se não houver a liberdade de desobedecer - comendo o fruto da árvore do conhecimento "do bem e do mal", tornaram-se humanos, emancipando-se da harmonia animal original com a natureza. Assim, ficaram conscientes de si mesmos e cada um do outro, passando a ter a consciência de que eram separados e de sua diferença. Porém, ao perceberem sua separação, permaneceram estranhos um para o outro, porque ainda não haviam aprendido a amar. Isso, de acordo com Fromm (1991), foi fonte de sua vergonha e culpa, e não o fato de estarem expostos seus órgãos genitais, como foi interpretado literalmente por muitas pessoas. Sendo assim, para Fromm (1991, p. 18), "A consciência da separação humana, sem a reunião pelo amor, é a fonte da vergonha. É ao mesmo tempo, a fonte da culpa e da ansiedade".
Essa fusão real, ou essa reunião pelo amor, só pode dar-se a partir do amor maduro. Para ele, qualquer tentativa de amar está fadada a falhar se esse amor não tiver uma orientação produtiva, ou seja, se não for desenvolvido no ser humano por meio de uma atitude ativa, certamente falhará.

Quando esclarece que o amor é uma atividade, Fromm, na mesma obra já citada, se refere a um ato de liberdade do homem, em que esse é senhor de seu afeto por meio da consciência.

Discordando da concepção de Freud, Fromm pontua que o amor - em sua forma madura, ou produtiva nunca se pode dar por meio de uma compulsão. Nesse caso, a compulsão à repetição, que é inconsciente e busca reeditar a experiência simbiótica da fase narcisista primária a partir da transferência.

Em contraste com o amor maduro ou ativo, está a forma passiva do amor, denominada por Fromm de união simbiótica. Nessa forma imatura de união, ambos os parceiros vivem num estado de codependência psíquica.

Fromm (1991, p. 32) afirma que "Em contraste com a união simbiótica, o amor amadurecido é união sob condição de preservar a integridade própria, a própria individualidade".

Surge assim mais uma discordância de Fromm, com relação às ideias de Freud, quando o primeiro desenvolve seu conceito de amor próprio. Freud concebe o amor próprio como sendo idêntico ao narcisismo. Em sua visão, o amor é a manifestação da libido que se volta para os outros, ou se volta para a própria pessoa. Assim sendo, amor e amor próprio são mutuamente exclusivos, ou seja, quanto mais houver de um, menos haverá do outro. Diferentemente de Freud, Fromm não vê o amor próprio como um vício e sim como uma virtude, por ser diferente do narcisismo. Este lhe atribui o papel oposto do egoísmo, dizendo que o egoísmo é causado pela falta de amor próprio, sendo o segundo precedente e primordial para qualquer outro tipo de amor.

Nesse sentido, Fromm define o amor como um "erguimento", e não como uma "queda". Sendo assim, para ele a paixão é uma forma passiva de amor, na qual a pessoa é escrava de seus afetos, não exercendo poder sobre esses, agindo, portanto, como um paciente e não como um "ator" perante seus próprios afetos.

Freud, a partir do conceito de idealização, como supervalorização de todas as características de um objeto amado, distingue amor de apaixonamento, 
definido o segundo como mais cego do que no caso do amor normal. Os dois permanecem ligados, e a diferença entre eles se mantém confusa ao longo de sua obra, sendo que muitas vezes o autor utilizou a expressão "paixão amorosa", o que demonstra essa ligação entre os conceitos, muitas vezes podendo ser vista como indistinção (Paz, 2009).

Lejarraga (2003 citado por Paz, 2009), com relação à visão de Freud sobre o apaixonamento e o amor, define o objeto da paixão como exclusivo, não havendo espaço para outros objetos na vida de um apaixonado. Isso acarreta como uma grande ameaça para o sofrimento, pois isso gera uma grande dependência do objeto pelo apaixonado, exercendo, nesse caso, o objeto grande poder sobre a vida deste. Já no amor haveria espaço para outros investimentos, além do objeto de amor.

Pontua-se que a maneira com que Freud define o amor é tida na visão de Fromm como paixão, ou amor imaturo. Este na visão de Freud, está ligado a aspectos inconscientes. Sendo assim, não são controlados pelo sujeito, mas sim o controlam, o indivíduo é afetado pela compulsão à repetição, buscando a partir da transferência um reencontro com os primeiros objetos perdidos e uma plenitude inalcançável.

Isto pode ser percebido com clareza quando, em crítica à metapsicologia do amor de Freud centrada no narcisismo, Fromm (1991, p. 144) diz:

"A capacidade de amar depende da capacidade de emergir do narcisismo e da fixação incestuosa à mãe e ao clã; depende de nossa capacidade de crescer, de desenvolver uma orientação produtiva em nossas relações para com o mundo e para conosco mesmo".

Portanto, pode-se considerar que a principal diferença na concepção de Freud e de Erich Fromm do amor é que, para Freud esse tem um caráter regressivo e repetitivo (Lejarraga, 2002), e para Fromm pode-se considerar que tem um caráter ativo e produtivo.

Para ambos os autores, o amor foi tema de grande importância, porém, para Freud, está ligado a um inconsciente libidinal, sustentado por uma energia sexual, sempre em busca de um objeto inexistente. Já para Fromm (1981), é tido como uma função de ego que deve ser desenvolvida até que se torne madura, uma conduta que se deve ter perante a vida, não tendo característica de exclusividade.
Tendo identificado os pontos discordantes entre esses dois autores acerca da temática do amor, devemos pontuar que ambos concordam que o amor é o viés para o crescimento e desenvolvimento humano. Para Freud, essa relação dar-se-á de forma satisfatória unicamente no processo psicanalítico, em que o analista tomará um caminho que não existe na vida real para o seu desenvolvimento (Ferreira, 2006); para Fromm (1991), o amor deverá acontecer nas relações cotidianas, não se limitando apenas ao setting terapêutico, e sim tomado como uma atitude perante a vida, uma arte que deve ser desenvolvida a cada dia, o que foi chamado por ele de psicanálise transterapêutica.

\section{Considerações finais}

O amor é tema de grande importância na vida humana e foi considerado tema de fundamental importância nas obras de grandes autores da teoria psicanalítica como Sigmund Freud e Erich Fromm. Dessa forma, deve ser digno de proporcional importância para a Psicologia, que é a ciência que estuda o comportamento humano, pois amar é uma ação humana.

Num diálogo entre Freud e Fromm acerca da temática do amor, identificamos muito mais pontos discrepantes do que de aproximação. Apesar de Fromm ter-se baseado nas ideias de Freud ao desenvolver as suas, este as fez por meio de uma dialética com as ideias marxistas, levando assim também em consideração os fatores sociais que exercem tensões sobre o ser humano além dos pulsionais. Assim sendo, Fromm concebe o amor como uma arte, ou seja, como uma atitude perante a vida, que não terá, dessa forma, caráter de exclusividade. Ao contrário da percepção de Freud acerca do tema, que identifica este como o depósito da libido em um objeto, associando-o muito mais a aspectos pulsionais que estão a serviço de um ideal narcísico perdido, do que ao desenvolvimento de potencialidade e amadurecimento de ego.

Assim sendo, para Freud, qualquer vínculo amoroso caracteriza-se por uma tentativa de reedição das primeiras experiências infantis da pessoa, estando a busca amorosa fadada ao fracasso, graças à impossibilidade de esse reencontro acontecer. Para Fromm, o amor é a única experiência sadia e satisfatória para a existência humana, sendo apenas por 
meio do desenvolvimento e da realização deste que o ser humano poderá ter uma existência plena.

Diante disso, observa-se que o amor é tema de suma importância em Psicologia, especificamente para a Psicanálise. Julga-se que o desenvolvimento de novos estudos sobre o amor com base nos mesmos autores aqui utilizados, bem como o esforço para o desenvolvimento de novos diálogos entre outros autores sobre a temática são importantes para a ampliação da discussão deste tema no meio acadêmico.

É também importante que se busque uma aproximação da temática voltando-as para as demandas oriundas do contexto social, tendo visto as diversas mudanças que aconteceram e continuam acontecendo na configuração das relações afetivo-amorosas, as quais poderiam se beneficiar das discussões sobre o amor elaboradas pela ciência psicológica.

\section{Referências}

Brito, B. P. M., \& Besset, V. L. (2008). Amor e saber na experiência analítica. Revista Mal-estar e Subjetividade, 8(3), 681-703.

Ferreira, V. (2006). Amor de transferência e a questão da cura na clínica psicanalítica. Psicologia.com.pt: O Portal Dos Psicólogos. Recuperado em 20 jul. 2009, em www.psicologia.com.pt

Fromm, E. (1981). 0 coração do homem: Seu gênio para o Bem e para o Mal (6a ed.). Rio de Janeiro: J. Zahar.

Fromm, E. (1991). A arte de amar. Belo Horizonte: Itatiaia.

Fromm, E. (1992). A descoberta do inconsciente social. São Paulo: Manole.
Freud, S. (1988). O mal-estar na civilização (1927-1931). Obras psicológicas completas Edição Standart (Vol. 21, pp. 67-147). Rio de Janeiro: Imago.

Freud, S. (1996). Observação sobre o amor transferencial (novas recomendações sobre a técnica da psicanálise III) [1911-1913]. Obras psicológicas completas Edição Standart (Vol. 22, pp. 177-188). Rio de Janeiro: Imago.

Freud, S. (1996). Três ensaios sobre a teoria da sexualidade (1901-1905). Obras psicológicas completas Edição Standart (Vol. 7, pp. 119-151). Rio de Janeiro: Imago.

Gil, A. C. (1991). Como elaborar projetos de pesquisa (3a ed.). São Paulo: Atlas.

Lejarraga, A. L. (2003). Freud e Winnicott: Do apaixonamento à capacidade de amar. Pulsional: Revista de Psicanálise, 16(165), 42-49.

Martins, G. de A., \& Pinto, R. L. (2001). Manual para elaboração de trabalhos acadêmicos. São Paulo: Atlas.

Paz, B. C. (2009). Freud e o Amor: Do ideal ao impossível - Um diálogo entre Psicanálise e Romantismo. Dissertação de Mestrado em Teoria Psicanalítica, Instituto de Psicologia da Universidade Federal do Rio de Janeiro, Rio de Janeiro.

Rios, I. C. (2008). O amor nos tempos de Narciso. Interface: Comunicação, Saúde, Educação, 12(25), 421-426.

Speller, M. A. R. (2001). Transferência e o que o banquete do amor tem a ver com isso? Pulsional: Revista de Psicanálise, 14(152), 102-111. 